\title{
Interleukin-11: A New Cytokine Critical for Osteoclast Development
}

\author{
G. Girasole, G. Passeri, R. L. Jilka, and S. C. Manolagas * \\ Section of Endocrinology and Metabolism, Veterans Affairs Medical Center, and Departments of Medicine and Biochemistry, Indiana \\ University, Indianapolis, Indiana 46202
}

\begin{abstract}
Stromal cells of the bone marrow control the development of osteoclasts through the production of cytokines capable of promoting the proliferation and differentiation of hematopoietic progenitors. Moreover, the deregulated production of the cytokine IL- 6 in the bone marrow mediates an increase in osteoclastogenesis after estrogen loss. IL-6, however, does not influence osteoclastogenesis in the estrogen-replete state, suggesting that other cytokines might be responsible for osteoclast development under physiologic circumstances. We report here that IL-11, a newly discovered cytokine that is produced by marrow stromal cells, induced the formation of osteoclasts exhibiting an unusually high degree of ploidy in cocultures of murine bone marrow and calvarial cells. Osteoclasts formed in the presence of IL-11 were capable of bone resorption, as evidenced by the formation of resorption pits, as well as the release of ${ }^{45} \mathrm{Ca}$ from prelabeled murine calvaria. Further, an antibody neutralizing IL-11 suppressed osteoclast development induced by either 1,25-dihydroxyvitamin $D_{3}$, parathyroid hormone, interleukin1, or tumor necrosis factor; whereas inhibitors of IL-1 or TNF had no effect on IL-11-stimulated osteoclast formation. The effects of IL-11 on osteoclast development were blocked by indomethacin; more important, however, they were independent of the estrogen status of the marrow donors. (J. Clin. Invest. 1994. 93:1516-1524.) Key words: 1,25-dihydroxyvitamin $D_{3} \cdot$ parathyroid hormone $\bullet$ interleukin-1 $\bullet$ tumor necrosis factor $\bullet$ interleukin- 6
\end{abstract}

\section{Introduction}

The replication and differentiation of hematopoietic cell precursors, including the progenitors of osteoclasts, is regulated by cytokines (1-5). Moreover, deregulated production of cytokines such as IL-6 seems to mediate an increase in osteoclastogenesis in certain states of pathologic bone resorption, including estrogen deficiency (6-9). Indeed, we had previously demonstrated that ovariectomy in mice causes an increase in the number of colony-forming units for granulocytes and macrophages (CFU-GM) ${ }^{1}$ the presumed osteoclast precursors in the

Address correspondence to Stavros C. Manolagas, M.D., Ph.D., Director, Division of Endocrinology and Metabolism, University of Arkansas for Medical Sciences, 4301 West Markham Street, Mail Slot 587, Little Rock, AR 72205.

Received for publication 2 July 1993 and in revised form 14 October 1993.

1. Abbreviations used in this paper: $\mathrm{CFU}-\mathrm{GM}$, colony-forming units for granulocytes and macrophages; $C T$, calcitonin; $1,25(\mathrm{OH})_{2} \mathrm{D}_{3}, 1,25$-dihydroxyvitamin $\mathrm{D}_{3}$; IL-1RA, IL-1 receptor agonist; rh, recombinant human; rm, recombinant murine; TRAPase, tartrate-resistant acid phosphatase.

The Journal of Clinical Investigation, Inc.

Volume 93, April 1994, 1516-1524 bone marrow, as well as an increase in the number of osteoclasts present in sections of trabecular bone; and that all these changes could be prevented by administration of $17 \beta$-estradiol or injections of an IL-6 neutralizing antibody (but not injections of an IgG isotype control antibody) to the ovariectomized animals (9). Consistent with these findings, we also demonstrated that estrogen loss causes an upregulation of IL-6 production by ex vivo bone marrow cell cultures in response to either 1,25-dihydroxyvitamin $\mathrm{D}_{3}\left[1,25(\mathrm{OH})_{2} \mathrm{D}_{3}\right]$ or PTH, and that a similar phenomenon can be elicited in vitro by withdrawal of $17 \beta$-estradiol from primary cultures of calvarial cells (10).

In our published in vivo studies, administration of the neutralizing antibody to IL-6 to sham-operated animals had no influence on osteoclastogenesis (9). This observation suggested that IL-6 may not play a critical role in osteoclast development under physiologic circumstances (i.e., the estrogen replete state), either because the system is redundant or because IL-6 levels in the marrow microenvironment are kept below a critical threshold relative to the sensitivity of osteoclastogenesis for IL-6. Therefore, we have hypothesized that other cytokines produced in the bone marrow microenvironment might be responsible for osteoclast development under physiologic circumstances.

IL-11 is a newly discovered cytokine that was identified in the culture medium from a primate stromal cell line capable of supporting hematopoiesis, and it was subsequently cloned from human fetal lung cells, as well as from a human bone marrow-derived cell line (11-13). Unlike other cytokines involved in hematopoiesis, IL-11 is not produced by T lymphocytes or monocytes, nor is it produced by liver, heart, or kidney cells (12), raising the possibility that it is a rather specific product of the mesenchymal cell lineage, which includes bone marrow stromal cells and osteoblasts. The DNA structure and the amino acid sequence of human IL-11 are completely distinct from those of human IL-6 (12-14). Yet, similar to IL-6, IL-1 1 acts synergistically with IL-3, IL-4, or steel factor to (a) stimulate CFU-GM formation in vitro; $(b)$ cause an increase in the number, size, and ploidy of megakaryocyte colonies; and (c) support the proliferation of macrophage colonies in the presence of erythropoietin (15-18).

Prompted by the common biologic properties of IL-11 and IL-6, we have investigated here whether IL-11 has a role in osteoclast development. The effect of IL-11 on osteoclast formation was examined in two in vitro systems commonly used for the study of osteoclastogenesis: $(a)$ murine bone marrow cells obtained from the femurs of adult female mice (19-21), and $(b)$ cocultures of bone marrow and calvaria cells from neonatal mice $(22,23)$. In both of these systems, osteoclast development from hematopoietic precursors depends on the presence of stromal/osteoblastic cells that provide the appropriate microenvironmental support (20-24). In cultures of marrow cells alone, the supportive cells are relatively few; this can be overcome by coculturing marrow cells with calvaria cells. In either system, osteoclast development can be induced by $1,25(\mathrm{OH})_{2} \mathrm{D}_{3}$ or PTH. 


\section{Methods}

Chemicals and reagents. Recombinant human IL-11 (rhIL-11), recombinant murine IL-11 (rmIL-11), and neutralizing monoclonal murine anti-human IL-11 were generously provided by Genetics Institute (Cambridge, MA). Recombinant human IL-1 $\beta$ (rhIL-1 $\beta$ ) was obtained from the Biological Resources Branch of the Biological Response Modifiers Program, Division of Cancer Treatment/National Cancer Institute (Frederick, MD) (specific activity $=1.8 \times 10^{7} \mathrm{U} /$ $\mathrm{mg})$. Recombinant murine TNF- $\alpha($ rmTNF- $\alpha)($ specific activity $=4$ $\times 10^{7} \mathrm{U} / \mathrm{mg}$ ) was purchased from Genzyme Corp. (Boston, MA). Recombinant murine IL-6 (specific activity $=2 \times 10^{7} \mathrm{U} / \mathrm{ml}$ ) was provided by DNAX Research Institute for Molecular and Cellular Biology (Palo Alto, CA) . 1,25( $\mathrm{OH})_{2} \mathrm{D}_{3}$ was provided by Dr. Milan Uskokovic (Hoffman-La Roche, Inc., Nutley, NJ). Synthetic bovine PTH(1-34) and synthetic salmon calcitonin (CT) were purchased from Peninsula Laboratories, Inc. (Belmont, CA). The neutralizing monoclonal rat antibody to murine IL-6, 20F3 (25), was provided by DNAX Research Institute for Cellular and Molecular Biology. Neutralizing monoclonal hamster antibody to murine $\operatorname{TNF}(\alpha+\beta)$ was purchased from Genzyme Corp. Recombinant human IL-1 receptor antagonist (IL-1RA) was purchased from R\&D Systems (Minneapolis, $\mathrm{MN}$ ). Nonimmune mouse IgG and nonimmune rat IgG were purchased from Accurate Chemical and Scientific Corp. (Westbury, NY). Indomethacin was purchased from Sigma Chemical Co. (St. Louis, MO).

Cells and culture conditions. Marrow cells were obtained from 5565-d-old (25-30 g) female Swiss Webster mice (Taconic Farms, Inc., Germantown, NY). Animals were housed and maintained in accordance with the National Institutes of Health Guide for the Care of Laboratory Animals. For the experiments investigating the impact of estrogen status on the osteoclastogenic effects of cytokines, the animals were sham ovariectomized, ovariectomized, or ovariectomized and implanted with slow-release pellets containing $0.01 \mathrm{mg}$ of $17 \beta$-estradiol (Innovative Research of America, Toledo, $\mathrm{OH}$ ), $4 \mathrm{wk}$ before isolation of marrow cells. To obtain marrow cells, the ends of a disarticulated femoral bone were cut, and the cells were flushed from the marrow with phenol red-free MEM (Gibco BRL, Gaithersburg, MD) containing $10 \%$ FCS (Sigma Chemical Co.) using a syringe fitted with a 25-gauge needle. After the cells were rinsed, the nucleated cell count was determined using a Coulter counter. The cells were then seeded at 1.5 $\times 10^{6} / 2-\mathrm{cm}^{2}$ well on $13-\mathrm{mm}$ round tissue culture coverslips (Thermanox; Nunc, Naperville, IL).

Calvaria cells were obtained by collagenase (CLS II; Worthington Biochemical Corp., Freehold, NJ) digestion of calvaria bone from 2- to 4-d-old C57Bl mice (26). Cells were initially seeded at $30,000 / \mathrm{cm}^{2}$ and grown to confluence in MEM containing $10 \%$ FCS. Calvaria cells were then harvested and reseeded together with the bone marrow cells $(0.05$ $\times 10^{6} / \mathrm{cm}^{2}$ marrow cells $+0.20 \times 10^{6} / \mathrm{cm}^{2}$ calvaria cells) in $2-\mathrm{cm}^{2}$ wells on 13-mm round Thermanox tissue cover slips.

Marrow cells or cocultures of marrow and calvaria cells were maintained at $37^{\circ} \mathrm{C}$ in $5 \% \mathrm{CO}_{2}$ for $9 \mathrm{~d}$ in MEM containing nonessential amino acids, $10 \% \mathrm{FCS}$, in the absence or presence of various hormones, cytokines, and antibodies. Every $3 \mathrm{~d}$, half of the medium was replaced with fresh medium.

Identification and quantitation of osteoclasts. Cell cultures were processed for autoradiographic detection of ${ }^{125} \mathrm{I}$-CT binding and tartrate-resistant acid phosphatase (TRAPase) as previously described (9). The total number of cells in each culture exhibiting both features were enumerated using bright field and dark field microscopy. Specific binding of ${ }^{125} \mathrm{I}-\mathrm{CT}$ was indicated by the absence of autoradiographic grains when the incubation with ${ }^{125} \mathrm{I}-\mathrm{CT}$ was carried out in the presence of $300 \mathrm{nM}$ unlabeled CT.

Assay of osteoclastic resorption pits. Cocultures of bone marrow cells and calvaria cells were established on top of $\sim 0.7 \mathrm{~cm}^{2}$ smooth cortical bone slices (kindly provided by K. Vanaanen, University of

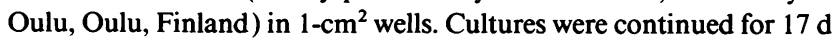

in the absence or presence of $500 \mathrm{pM}$ rhIL-11. Half of the medium was changed every $3 \mathrm{~d}$ during the culture period. Upon the completion of the culture, the bone slices were sonicated in $0.1 \mathrm{M} \mathrm{NH}_{4} \mathrm{OH}$ to destroy the cells, and after rinsing and drying, they were sputter-coated with gold-palladium for examination by scanning electron microscopy or polarized reflected light microscopy $(27,28)$. In the latter, resorption pits were recognized by their dark appearance on a bright background, and the excavated surface area was quantitated by a semiautomated image analysis program (ImageMeasure/IP 5200; Microscience Inc., Federal Way, WA). Repeated measures of the same collection of pits indicated a variability of $<2 \%$.

Assay of bone resorption by ${ }^{45}$ Ca release. 2 -d-old C57Bl mice were injected subcutaneously with $2 \mu \mathrm{Ci}$ of ${ }^{45} \mathrm{Ca}$ to label the bone matrix. 24 $\mathrm{h}$ after injection, calvaria were dissected and divided into hemicalvarial parietal bones. Each bone explant was then used for the bone resorption assay. During the assay, the explants were cultured individually at $37^{\circ} \mathrm{C}$ in $5 \% \mathrm{CO}_{2}$ and $50 \% \mathrm{O}_{2}$ in air in MEM containing $10 \%$ horse serum (Sigma Chemical Co.) and 2.5\% FCS, in the absence or in the presence of rhIL-11 or rhIL-11 and CT, with replacement of old media with fresh every $2 \mathrm{~d}$. After $8 \mathrm{~d}$ of culture, bone explants were placed in $0.1 \mathrm{~N} \mathrm{HCl}$. The amount of ${ }^{45} \mathrm{Ca}$ released into the medium and the amount remaining in the bone explant were determined by counting an aliquot of the culture supernatant and the acid extract, respectively, using a scintillation counter.

IL-11 bioassay. IL-11 was quantified by measuring the proliferative response of B9/11 cells (generously provided by Dr. Bernard Klein, University of Nantes, Nantes, France). Because IL-6 also stimulates the proliferation of $\mathrm{B} 9 / 11$ cells, this assay was performed in the presence of $35 \mu \mathrm{g} / \mathrm{ml}$ of a neutralizing monoclonal rat antibody to murine IL-6; this concentration of antibody is sufficient to block the bioactivity of $1.4 \mathrm{nM}$ rmIL-6 in this bioassay. B9/11 cells $\left(1 \times 10^{4} /\right.$ well of a 96-well plate) were cultured for a total of $72 \mathrm{~h}$ with serial dilutions of culture supernatant in a final volume of $200 \mu \mathrm{l}$ of RPMI 1640 medium (Gibco BRL) containing $5 \times 10^{-5} \mathrm{M}$ 2-mercaptoethanol and $10 \%$ FCS (Hyclone Laboratories, Logan, UT). Each dilution was assayed in duplicate. $8 \mathrm{~h}$ before the end of the bioassay, $0.5 \mu \mathrm{Ci}$ of $\left[{ }^{3} \mathrm{H}\right]$ thymidine was added. The cells were then harvested and the incorporated radioactivity determined. The amount of IL-11 present in the culture supernatant was determined using a standard curve set up with known amounts of rmIL-11.

Statistics. Unless indicated otherwise, data were analyzed by Student's $t$ test or analysis of variance. For the analysis of variance, Dunnet's test, or the least significant difference approach was used to test for differences between means.

\section{Results}

Addition of rhIL-11 to marrow cells cultured alone had no effect on osteoclast development (Table I). However, rhIL-11 stimulated osteoclast formation in cocultures of marrow and calvaria cells over a range of concentrations (17-500 pM) and in a dose-dependent fashion. In three separate experiments, the number of osteoclasts formed in the presence of $500 \mathrm{pM}$ rhIL11 was two- to fivefold greater than the number of osteoclasts formed in the presence of $10 \mathrm{nM} 1,25(\mathrm{OH})_{2} \mathrm{D}_{3}$ or $10 \mathrm{nM}$ PTH. Although IL-11 did not stimulate osteoclast development in marrow cells cultured alone, when rhIL-11 (500 pM) was com-

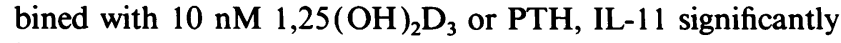
increased the number of osteoclasts induced in the marrow cell cultures by either $1,25(\mathrm{OH})_{2} \mathrm{D}_{3}$ or PTH from $175 \pm 57(\mathrm{SD})$ to $303 \pm 60$, and $111 \pm 40$ to $227 \pm 65$, respectively $(P<0.05)$.

In the cocultures of calvaria and marrow cells treated with rhIL-11, we consistently observed the presence of very large osteoclasts compared to the osteoclasts that are typically formed in the presence of $10 \mathrm{nM} 1,25(\mathrm{OH})_{2} \mathrm{D}_{3}$ (Fig. 1). Moreover, as illustrated in Fig. 2, the number of osteoclasts bearing 
Table I. Effect of rhIL-11 on Osteoclast Development in Murine Bone Marrow Cell Cultures and Cocultures of Bone Marrow and Calvaria Cells

\begin{tabular}{|c|c|c|}
\hline \multirow[b]{2}{*}{ Treatment } & \multicolumn{2}{|c|}{ Osteoclasts/well } \\
\hline & Marrow cells & $\begin{array}{l}\text { Marrow cells + } \\
\text { calvaria cells }\end{array}$ \\
\hline None & $12 \pm 4$ & $11 \pm 2$ \\
\hline rhIL-11 17 pM & - & $30 \pm 26$ \\
\hline rhIL-11 $50 \mathrm{pM}$ & - & $196 \pm 28$ \\
\hline rhIL-11 $150 \mathrm{pM}$ & - & $436 \pm 41$ \\
\hline rhIL-11 $500 \mathrm{pM}$ & $13 \pm 8$ & $809 \pm 80$ \\
\hline
\end{tabular}

Marrow cell cultures and cocultures of marrow cells and calvaria cells were maintained for $9 \mathrm{~d}$ in the absence (None) or in the presence of the indicated concentrations of rhIL- 11 . Then, cells were processed for enumeration of osteoclasts (cells exhibiting both staining for TRAPase and iodinated calcitonin binding, as detailed in Methods). Each value represents the mean \pm SD of osteoclasts per well of three to four replicate cultures per condition. Few, if any, osteoclasts formed when rhIL-11 was added to calvaria cells cultured without marrow cells. Essentially identical results were obtained in two replicate experiments.

greater than three nuclei was fourfold greater than that of $1,25(\mathrm{OH})_{2} \mathrm{D}_{3}$-treated cultures ( 36 vs $9 \% ; P<0.001$ ).

To establish the ability of the osteoclasts formed in the presence of rhIL-11 to resorb bone, cocultures of murine marrow cells and calvaria cells were grown for $17 \mathrm{~d}$ on top of smooth bovine cortical bone slices $\left(\sim 0.7 \mathrm{~cm}^{2}\right)$, which were then examined by scanning electron microscopy for the presence of resorption pits $(27,28)$. As indicated by the data summarized in Table II, the number of pits formed and the area excavated by osteoclasts from the surface of the bone slice was dramatically increased upon stimulation with rhIL-11. A representative image of authentic resorption pits characteristic of osteoclastic bone resorption is shown in Fig. $3 A$. Furthermore, rhIL-11 caused a dose-dependent increase in the release of ${ }^{45} \mathrm{Ca}$ from prelabeled neonatal murine calvaria over a similar range of concentrations to the range required for osteoclast development (Fig. $3 B$ ). The stimulatory effect of rhIL-11 at its maximal concentration was significantly decreased in the presence of calcitonin, an established inhibitor of osteoclastic bone resorption.

In view of the ability of rhIL-11 to induce osteoclast formation, we investigated the possibility that endogenously produced IL-11 in the bone marrow microenvironment plays a role in osteoclastogenesis. To do this, we used an IL-11-specific bioassay, which is based on the proliferative response of the hybridoma cell line, B9/11, to exogenous IL-11. As shown in Fig. 4, B9/11 cells exhibit a dose-dependent proliferative response to rmIL-11, but not to $1,25(\mathrm{OH})_{2} \mathrm{D}_{3}$, PTH, $17 \beta$ estradiol, rhIL- $1 \beta$, rmTNF- $\alpha$, or TGF- $\beta$. The specificity of the B9 / 11 cell response to rmIL-11, was further confirmed by demonstrating that a murine anti-human IL-11 neutralizing monoclonal antibody completely suppressed the stimulatory effect of rmIL-11 (as well as rhIL-11, not shown), in a titration-dependent fashion. Moreover, the anti-IL-1 1 antibody had no effect on the ability of rmIL-6 to stimulate B9/11 cell proliferation.

Using this IL-11 bioassay, we found that culture superna- tants from marrow cells maintained in the presence of either $1,25(\mathrm{OH})_{2} \mathrm{D}_{3}$ or PTH contained significant amounts of bioassayable IL-11, and that addition of the IL-11 neutralizing antibody to the culture supernatants before bioassay completely suppressed this activity (Fig. 5). On the other hand, culture supernatants from unstimulated marrow cells contained no IL-11.

In view of the above evidence, we examined the ability of the IL-11 neutralizing antibody to inhibit osteoclast formation. As the data in Table III indicate, the anti-IL-11 antibody inhibited $1,25(\mathrm{OH})_{2} \mathrm{D}_{3}$-stimulated osteoclast formation in a dosedependent fashion. Indeed, based on the amount of IL-11 detected in culture supernatants of the experiment shown in Fig. 5 , one would predict that $\sim 1-5 \mu \mathrm{g} / \mathrm{ml}$ of anti-IL-11 would indeed be required to neutralize the activity of IL-11 present in these $1,25(\mathrm{OH})_{2} \mathrm{D}_{3}$-treated marrow cell cultures. In additional experiments using cocultures of marrow cells and calvaria cells ( Table IV), we found that the anti-IL-11 antibody, but not an IgG isotype control, completely suppressed osteoclast formation induced not only by $1,25(\mathrm{OH})_{2} \mathrm{D}_{3}$, but also by PTH. Furthermore, the anti-IL-11 antibody partially inhibited osteoclast development induced by either rhIL- $\beta$ or rmTNF- $\alpha$, indicating a critical role of IL-1 1 in the osteoclastogenic effects of both systemic hormones and locally produced cytokines. In contrast to the finding for a partial dependency of the IL-1- or TNF-induced osteoclast development on IL-11, the IL-11-induced osteoclast development was not affected by the IL-1 receptor antagonist (or a neutralizing antibody against murine IL- $\alpha$; not shown) or by a neutralizing antibody against both TNF $\alpha$ and TNF $\beta$. Therefore, the osteoclastogenic effects of IL-1 1 do not seem to require IL-1 or TNF. In experiments not shown, we have also examined the effect of the IL- 6 neutralizing antibody on IL-1-, TNF-, and IL-11-induced osteoclast development using identical cocultures to those shown in Table IV; i.e., murine bone marrow and calvaria cells. We found that the IL-6 neutralizing antibody was completely ineffective under these experimental conditions.

Because of evidence that prostaglandins are essential for the effects of $1,25(\mathrm{OH})_{2} \mathrm{D}_{3}$, as well as cytokines such as IL-1, on osteoclast development $(29,30)$, we also examined the requirement for prostaglandins in the osteoclastogenic effects of IL-1 1 . As shown by the data of Fig. 6, we found that IL-11-stimulated osteoclast formation was suppressed, in a dose-dependent fashion, by the cyclooxygenase inhibitor indomethacin. Thus, prostaglandins are likely involved in the stimulatory effect of IL-11 on osteoclast formation.

Similar to the results of the cocultures of marrow and calvaria cells, the anti-IL-11 antibody prevented osteoclast formation induced by $1,25(\mathrm{OH})_{2} \mathrm{D}_{3}$ or PTH in cultures of marrow cells alone (Table V). This inhibitory effect of the antibody on osteoclastogenesis induced in bone marrow cells cultured alone was seen in cultures of bone marrow cells obtained from mice that were either sham-operated, ovariectomized, or ovariectomized and treated with estrogen. In contrast to the IL- 11 antibody, a neutralizing antibody against IL-6 had no effect on osteoclast formation in marrow cells obtained from sham-operated, or ovariectomized mice receiving estrogen treatment. Yet, the anti-IL-6 antibody prevented the increased osteoclast formation exhibited by marrow cells from ovariectomized animals (i.e., returned osteoclast levels to those of the sham-operated animals), as we had previously observed 
A

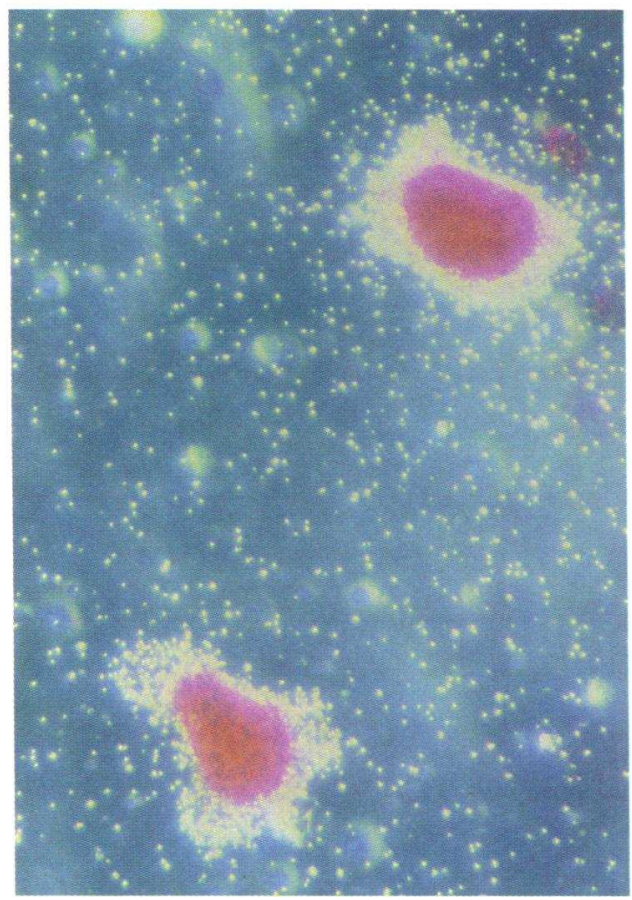

C

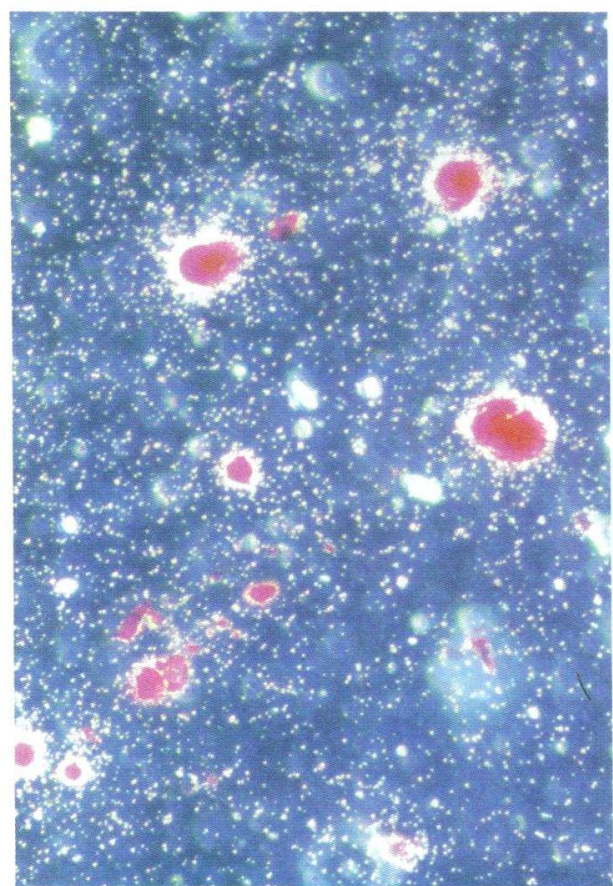

B

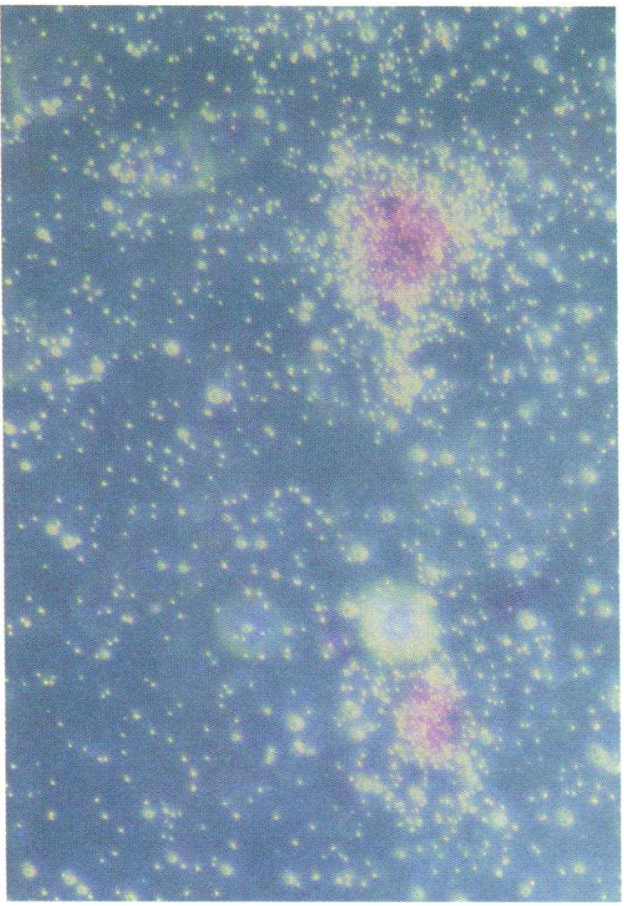

D

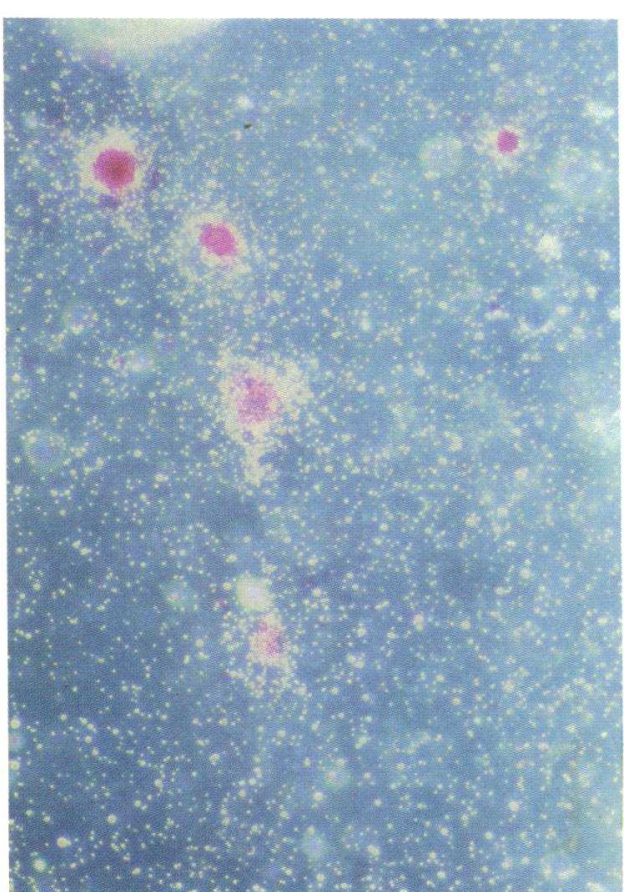

Figure 1. Effects of rhIL-11 on the morphology of osteoclasts. Cocultures of bone marrow cells and calvaria cells were maintained in the presence of $500 \mathrm{pM}$ rhIL-11 $(A$ and $C)$ or $10^{-8} \mathrm{M} 1,25(\mathrm{OH})_{2} \mathrm{D}_{3}(B$ and $D)$. Microphotographs of representative osteoclasts obtained using darkfield microscopy at $\times 280(A$ and $B)$ and $\times 140(C$ and $D)$ are shown. TRAPase staining is represented by the red color and ${ }^{125}$ I-CT binding is represented by the white grains. 


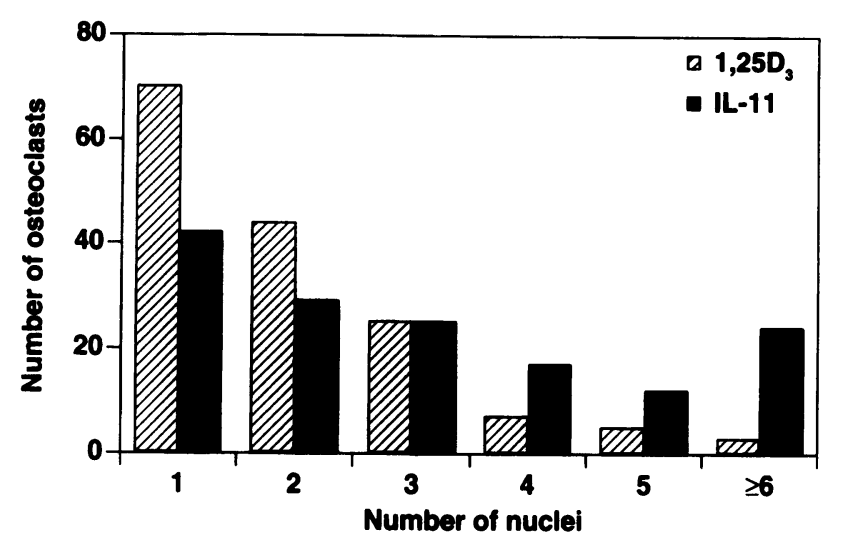

Figure 2. Frequency distribution of the ploidy of osteoclasts induced by $1,25(\mathrm{OH})_{2} \mathrm{D}_{3}$ vs IL-11. Cocultures of marrow cells and calvaria cells were maintained for $9 \mathrm{~d}$ in the presence of either $10 \mathrm{nM}$ $1,25(\mathrm{OH})_{2} \mathrm{D}_{3}$, or $500 \mathrm{pM}$ rhIL-11. The cells were then processed for identification of osteoclasts. The number of nuclei per osteoclast was determined using phase contrast microscopy in 150 randomly selected TRAPase-positive cells exhibiting autoradiographic grains caused by ${ }^{125} \mathrm{I}-\mathrm{CT}$ binding. Chi square analysis indicated that the frequency distribution of the ploidy of osteoclasts induced by $1,25(\mathrm{OH})_{2} \mathrm{D}_{3}$ was significantly different from the frequency distribution of the ploidy of osteoclasts induced by rhIL-11 $(P<0.001)$.

(9), confirming our contention that IL-6 is involved in osteoclastogenesis in the estrogen deplete state, but not in the estrogen-replete state.

Nonimmune mouse IgG or nonimmune rat IgG used as the respective isotype controls for anti-IL-1 1 and anti-IL-6 antibody, respectively, had no effect on osteoclast development induced by PTH or $1,25(\mathrm{OH})_{2} \mathrm{D}_{3}$. In addition, the anti-IL-1 1 antibody did not have adverse effects on cell viability, or the ability of stromal / osteoblastic cells to produce IL-6 in response to IL-1 or TNF in either murine calvaria cell cultures or bone marrow-derived stromal cells (MBA 13.2) (data not shown). Therefore, the possibility that the anti-IL-11 antibody has nonspecific or cytotoxic effects in these experiments is extremely unlikely.

Table II. Effect of rhIL-11 on Pit Formation by Cocultures of Marrow Cells and Calvaria Cells

\begin{tabular}{lcc}
\hline Treatment & $\begin{array}{c}\text { Number of } \\
\text { pits/slice }\end{array}$ & $\begin{array}{c}\text { Area } \\
\text { resorbed/slice } \\
\left(\times 10^{-3} \mu \mathrm{m}^{2}\right)\end{array}$ \\
\hline None & $0.3 \pm 0.5$ & $4.2 \pm 6.0$ \\
rhIL-11 & $142 \pm 22^{*}$ & $185 \pm 51^{*}$
\end{tabular}

Cocultures of marrow cells and calvaria cells were maintained for $17 \mathrm{~d}$ on top of $0.7 \mathrm{~cm}^{2}$ smooth cortical bone slices in the absence (None) or the presence of $500 \mathrm{pM}$ rhIL-11. Half of the media was replaced every $3 \mathrm{~d}$. At the end of the culture period, the cells were removed and the bone slices were processed to visualize resorption pits. The number of pits formed and the total surface area excavated from each slice was quantified by image analysis, as detailed in Methods. Data shown represent the mean \pm SD of triplicate cultures. ${ }^{*} P<0.001$ vs cells cultures in the absence of rhIL-11 (None).
A
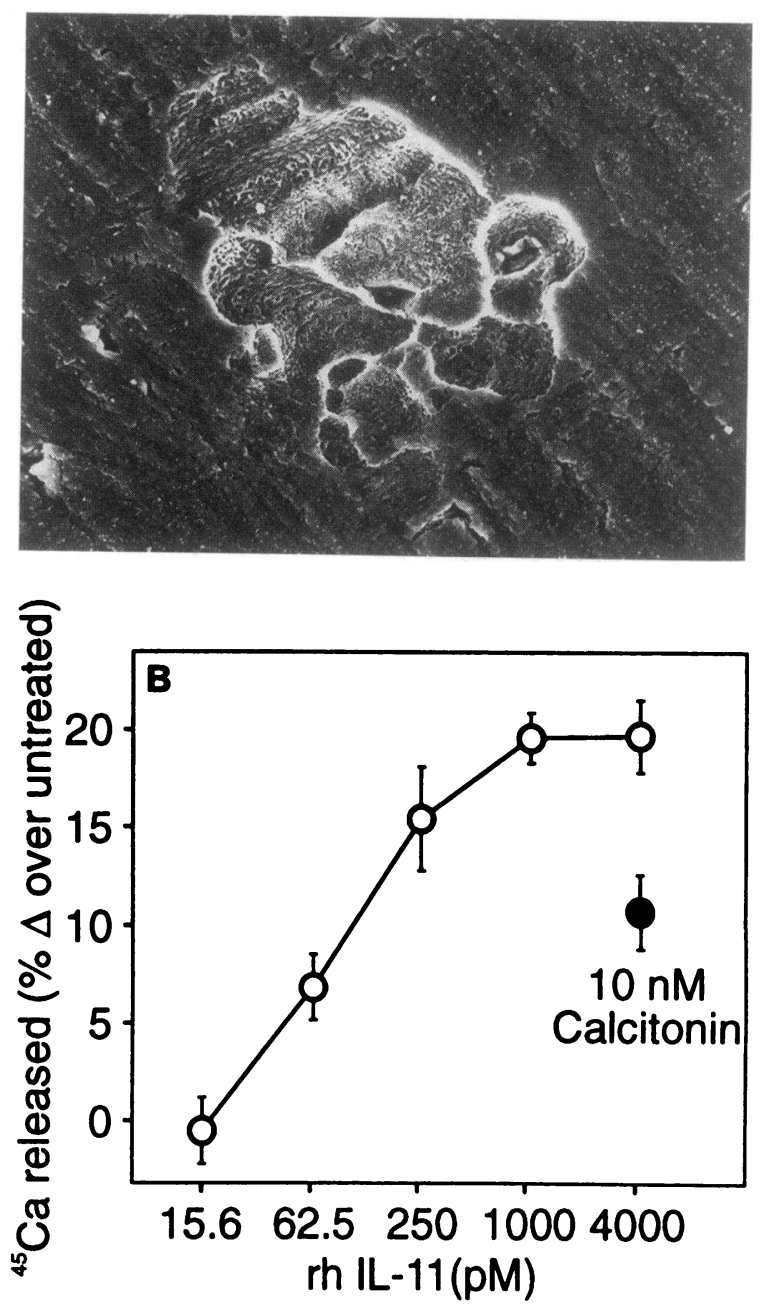

Figure 3. Effect of rhIL-11 on osteoclastic bone resorption. (A) Scanning electron microphotograph $(\times 650)$ of osteoclast resorption pits formed on the surface of smooth cortical bone slices. Cocultures of bone marrow cells and calvaria cells were established on top of $\sim 0.7$ $\mathrm{cm}^{2}$ smooth cortical bone slices (kindly provided by $\mathrm{K}$. Vanaanen, University of Oulu, Oulu, Finland) and continued for $17 \mathrm{~d}$ in the presence of $500 \mathrm{pM}$ rhIL-11. The bone slice was processed for scanning electron microscopy to visualize pits formed on the surface. $(B)$ Stimulation of ${ }^{45} \mathrm{Ca}$ release from prelabeled neonatal murine calvaria by rhIL-11. Neonatal murine calvaria (six replicate cultures per treatment group), labeled with ${ }^{45} \mathrm{Ca}$, were maintained in the absence (basal) or presence of the indicated amounts of rhIL-11 for $8 \mathrm{~d}$. An additional set of calvaria was maintained in the presence of the combination of $4,000 \mathrm{pM}$ rhIL-11 and $10 \mathrm{nM} \mathrm{CT}$. At the end of the culture period, the percentage of the ${ }^{45} \mathrm{Ca}$ released from each bone during culture was determined. Each point represents the net mean \pm SD percentage of the ${ }^{45} \mathrm{Ca}$ released, obtained by subtracting the mean percentage of the ${ }^{45} \mathrm{Ca}$ released under basal conditions from that released in the presence of rhIL-11. The ${ }^{45} \mathrm{Ca}$ released from calvaria maintained in the presence of 4,000 pM rhIL-11 vs calvaria maintained in the presence of $4,000 \mathrm{pM}$ rhIL-11 and CT was significantly different (Student's $t$ test, $P<0.05$ ).

\section{Discussion}

Evidence for the similarity of the biologic properties of IL-11 and IL-6 in certain aspects of hematopoiesis (15-18), and the evidence indicating that IL-11 is produced by mesenchymalderived stromal cells of the bone marrow (11-13) have 


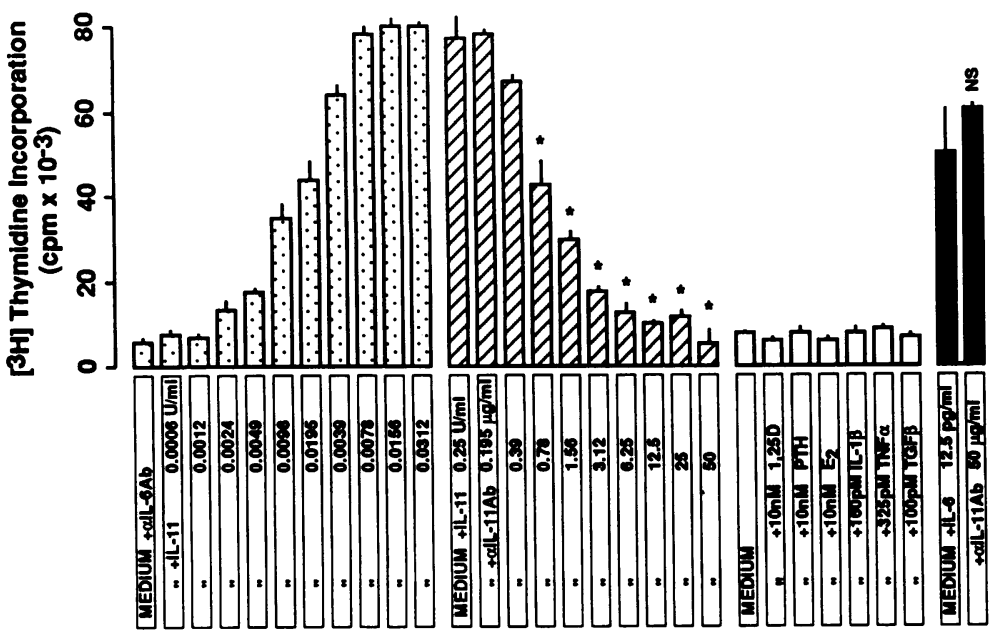

Figure 4. Specificity of the B9/11 bioassay for IL-11. Dose response of the $\mathrm{B} 9 / 11$ cell proliferation to rmIL-11 (stippled bars); the effect of a neutralizing monoclonal murine anti-human IL-11 antibody on this response (diagonally striped bars); the lack of effect of various hormones and cytokines on this response (open bars); the lack of effect of the IL-11 neutralizing antibody on the response of B9/11 cell proliferation to rmIL- 6 (filled bars). ${ }^{*} P<0.05$ vs cells cultured in the absence of the anti-IL-11 antibody; NS, not significantly different from cells cultured in the absence of the anti-IL-11 antibody.

prompted us to investigate whether IL-11 plays a role in osteoclastogenesis. The results presented in this study demonstrate that IL-11 is indeed a potent inducer of osteoclast development as evidenced by its ability to induce osteoclastogenesis and bone resorption at concentrations as low as $50 \mathrm{pM}$. In addition, the findings of this paper indicate that IL-11 production by bone marrow cells can be stimulated by $1,25(\mathrm{OH})_{2} \mathrm{D}_{3}$ and PTH, and that neutralization of IL-11 in bone marrow cell cultures suppresses the ability of either hormone to induce osteoclast development. We also found that, as is the case for the osteoclastogenic effects of $1,25(\mathrm{OH})_{2} \mathrm{D}_{3}$ and IL-1 $(29,30)$, the ability of IL-11 to stimulate osteoclast formation is likely dependent on prostaglandins.

The evidence that $1,25(\mathrm{OH})_{2} \mathrm{D}_{3}$ and PTH stimulated IL-1 1 production, and that an anti-IL-11 monoclonal antibody completely suppressed the osteoclastogenic effect of $1,25(\mathrm{OH})_{2} \mathrm{D}_{3}$,

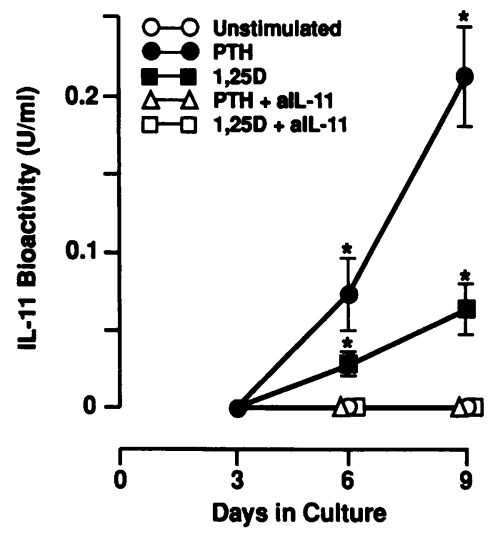

Figure 5. Effect of $1,25(\mathrm{OH})_{2} \mathrm{D}_{3}$ or PTH on IL-11 production by bone marrow cells. Marrow cells were cultured for $9 \mathrm{~d}$ in the absence (unstimulated) or in the presence of 10 $\mathrm{nM} 1,25(\mathrm{OH})_{2} \mathrm{D}_{3}$ $(1,25 \mathrm{D})$ or $10 \mathrm{nM}$ PTH. Every $3 \mathrm{~d}$, half of the medium was replaced with fresh medium. IL11 in the culture supernatants was determined using the $\mathrm{B} 9 / 11$ bioassay, conducted in the absence or in the presence of $6 \mu \mathrm{g} / \mathrm{ml}$ of neutralizing monoclonal murine antibody against IL-11 (aIL-11). To calculate the cumulative amount of IL-11 produced by the cultures, the amount of IL-11 present in the culture supernatants obtained 6 and $9 \mathrm{~d}$ after initiation of the culture was corrected by adding $50 \%$ of the value obtained at the preceding time point to the absolute value determined at the subsequent time point. Each point represents the mean cumulative IL-11 ( $\pm \mathrm{SD})$ of triplicate cultures. ${ }^{*} P<0.05$ vs unstimulated cultures. taken together with the observation that both $1,25(\mathrm{OH})_{2} \mathrm{D}_{3}-$ and IL-11-induced osteoclast development involves prostaglandins, suggests that IL- 11 is an essential factor for the osteoclastogenic effect of $1,25(\mathrm{OH})_{2} \mathrm{D}_{3}$ in the murine system. Nonetheless, we have found that unlike $1,25(\mathrm{OH})_{2} \mathrm{D}_{3}$ and PTH, which can induce osteoclast development in bone marrow cell cultures, IL-11 has no effect on osteoclast formation in such cultures, unless marrow cells are cultured with calvaria cells. This evidence suggests that IL-11 can induce osteoclastogenesis only in the presence of an appropriate environment that is not provided by marrow cells when cultured alone. In addition, we found that IL-11-induced osteoclasts exhibit greater ploidy as compared to osteoclasts induced by $10^{-8} \mathrm{M} 1,25(\mathrm{OH})_{2} \mathrm{D}_{3}$. Even though such comparison is arbitrary given the fact that the endogenous levels of IL-11 in the murine marrow is not established, it is worth noting that in the ploidy experiments, we have compared concentrations of either agent that induce maximal numbers of osteoclasts in these culture systems. Based on these considerations, one has to conclude that IL-11 is unlikely to be the sole mediator of the osteoclastogenic effects of $1,25(\mathrm{OH})_{2} \mathrm{D}_{3}$ or PTH. Instead, IL-11 may be an essential cofactor of osteoclast development acting in concert with $1,25(\mathrm{OH})_{2} \mathrm{D}_{3}, \mathrm{PTH}$, and other factors produced locally by

Table III. Effect of Monoclonal Antibody to IL-11 on $1,25(\mathrm{OH})_{2} D_{3}$-stimulated Osteoclast Formation in Murine Bone Marrow Cell Cultures

\begin{tabular}{lc}
\hline \multicolumn{1}{c}{ Addition } & Osteoclasts/well \\
\hline $1,25(\mathrm{OH})_{2} \mathrm{D}_{3}$ & $180 \pm 37$ \\
$1,25(\mathrm{OH})_{2} \mathrm{D}_{3}+1.5 \mu \mathrm{g} / \mathrm{ml}$ anti-IL-11 & $207 \pm 28$ \\
$1,25(\mathrm{OH})_{2} \mathrm{D}_{3}+3.0 \mu \mathrm{g} / \mathrm{ml}$ anti-IL-11 & $86 \pm 27^{*}$ \\
$1,25(\mathrm{OH})_{2} \mathrm{D}_{3}+6.0 \mu \mathrm{g} / \mathrm{ml}$ anti-IL-11 & $19 \pm 8^{*}$
\end{tabular}

Marrow cells were maintained for $9 \mathrm{~d}$ in the presence of $10 \mathrm{nM}$ $1,25(\mathrm{OH})_{2} \mathrm{D}_{3}$ without or with the indicated amount of neutralizing monoclonal murine antibody to IL-11. Values shown represent the mean \pm SD number of osteoclasts per well from 2-3 replicate cultures. ${ }^{*} P<0.05$ vs cells maintained in $1,25(\mathrm{OH})_{2} \mathrm{D}_{3}$ without anti-IL-11. 
Table IV. Effect of Monoclonal Antibody to IL-11 on Osteoclast Development Induced by Systemic Hormones or Other Cytokines in Cocultures of Bone Marrow and Calvaria Cells

\begin{tabular}{llccc}
\hline & & \multicolumn{3}{c}{ Osteoclasts/well } \\
\cline { 3 - 5 } Experiment 1 & Antibody & Basal & $1,25(\mathrm{OH})_{2} \mathrm{D}_{3}$ & PTH \\
\hline & IgG & $1 \pm 1$ & $36 \pm 5$ & $54 \pm 21$ \\
& IL-11 mAb & $<1$ & $2 \pm 1^{*}$ & $4 \pm 3^{*}$ \\
Experiment 2 & Antibody & rhIL-11 & rhIL-1 $\beta$ & rmTNF- $\alpha$ \\
\hline & None & $300 \pm 25$ & $574 \pm 93$ & $378 \pm 100$ \\
& IL-11 mAb & $<1^{*}$ & $266 \pm 61^{\ddagger}$ & $109 \pm 29^{\ddagger}$ \\
& IL-1RA & $247 \pm 37$ & $<1^{*}$ & $501 \pm 112$ \\
& TNF $(\alpha+\beta)$ mAb & $408 \pm 83^{\ddagger}$ & $432 \pm 130$ & $102 \pm 64^{\ddagger}$ \\
& & & & \\
\hline
\end{tabular}

In Experiment 1, cocultures of marrow cells and calvaria cells were maintained in the absence (basal) or presence of $10 \mathrm{nM} 1,25(\mathrm{OH})_{2} \mathrm{D}_{3}$ or $10 \mathrm{nM}$ PTH for $9 \mathrm{~d}$. Half of the cultures also contained $6 \mu \mathrm{g} / \mathrm{ml}$ of nonimmune mouse IgG, whereas the other half contained $6 \mu \mathrm{g} / \mathrm{ml}$ of a neutralizing monoclonal murine antibody to IL-11. In Experiment 2 , cocultures were maintained in the presence of either $500 \mathrm{pM}$ rhIL-11, $50 \mathrm{pM}$ rhIL- $1 \beta$, or $35 \mathrm{pM} \mathrm{rmTNF} \alpha$ in the absence (None) or in the presence of $6 \mu \mathrm{g} / \mathrm{ml}$ of the neutralizing monoclonal murine antibody to IL- 11 , or $17 \mu \mathrm{g} / \mathrm{ml}(1 \mu \mathrm{M})$ IL-1RA, or $5 \mu \mathrm{g} / \mathrm{ml}$ of a neutralizing monoclonal hamster anti-murine $\operatorname{TNF}(\alpha+\beta)$ antibody. The concentrations of the antibodies and the IL-1RA used in these experiments were based on the results of pilot studies or the suppliers' recommendations, and were sufficient to block $3.3 \mathrm{nM}$ rhIL-11, 1 nM murine IL-1, or 35 pM TNF, respectively. Each value represents the mean \pm SD osteoclast number (cells exhibiting both TRAPase staining and ${ }^{125}$ I-CT binding) per well from four replicate cultures. Statistically significant differences from either the IgG control (Experiment 1) or the untreated control group (None, Experiment 2) are indicated. ${ }^{*} P<0.01,^{\ddagger} P<0.05$. Essentially identical results were obtained in two additional experiments.

stromal/osteoblastic cells, including intercellular signals generated by direct contact of the these cells with the hematopoietic precursor of the osteoclast $(22,24)$.

Even though IL-11 shares several properties with IL-6, the results presented in this paper provide evidence suggesting that there is a distinction between the role of IL-11 and IL- 6 in osteoclast development. Specifically, the demonstration of the ability of the anti-IL-11 antibody to suppress osteoclast development in bone marrow cultures from both estrogen-deficient and estrogen-replete animals suggests that IL-1 1 is essential for osteoclastogenesis in general. On the other hand, IL-6 seems to attain its importance for osteoclastogenesis only in the estrogen-deficient state, as evidenced by the inability of the anti-IL6 antibody to affect osteoclast formation in cultures from estrogen-replete animals, whereas it prevented the increased osteoclast development exhibited by bone marrow cultures from estrogen-deficient animals. The evidence against a role of IL-6 in osteoclast development under physiologic conditions (i.e., the estrogen replete state) is confirmatory of our previous observations in vitro, as well as in vivo (9).

The findings of this study indicate further that the osteoclastogenic properties of IL-11 are distinct from the properties of other cytokines known to affect osteoclast formation, besides IL-6. Indeed, the observation that the effects of IL-1 or TNF on osteoclast development depend, in part, on IL-11, whereas the effect of IL-11 is independent of IL-1 or TNF, indicate that IL-11 must provide a more complete and hierarchically more central signal for osteoclast formation, as compared to the signals of IL-1 and TNF. Unlike IL-11, which is produced by mesenchymal-derived adherent cells (11-13), the primary cellular source of IL-1 and TNF in the marrow is most likely the monocyte/macrophage (31). Considering this, and the requirement of cell-to-cell contact between osteoclast progenitors and stromal/osteoblastic cells for osteoclast formation $(22,24)$, it is likely that the IL-11 signal for osteoclast development is juxtacrine, as opposed to the IL-1 and TNF signals that may be paracrine.

The ability of IL-1 1 to induce osteoclast development when added to cocultures of marrow and calvaria cells by itself, also sets it apart from several other cytokines. Indeed, unlike IL-11, the cytokines IL-6, IL-3, or granulocyte/macrophage-colony stimulating factor do not induce osteoclast development by themselves in these cultures (Girasole, G., G. Passeri, R. L. Jilka, and S. C. Manolagas, unpublished observations). Finally, macrophage-colony stimulating factor, a cytokine that appears to be essential for osteoclastogenesis (32-35) inhibits $1,25(\mathrm{OH})_{2} \mathrm{D}_{3}$-induced osteoclast development in marrow cell cultures (36), as opposed to our findings here that IL-11 enhances the osteoclastogenic effects of $1,25(\mathrm{OH})_{2} \mathrm{D}_{3}$.

In conclusion, the results presented in this study demonstrate that IL-11 is an important new member of the cytokine network that controls osteoclast development. Moreover, based on the evidence discussed above, our observations strongly suggest that IL-11 has distinct properties compared to other cytokines, and that IL-11 plays a hierarchically central role in osteoclast formation. More extensive studies will be required to determine the precise role of IL-11 in the osteoclastogenic effects of systemic hormones and other locally produced cytokines.

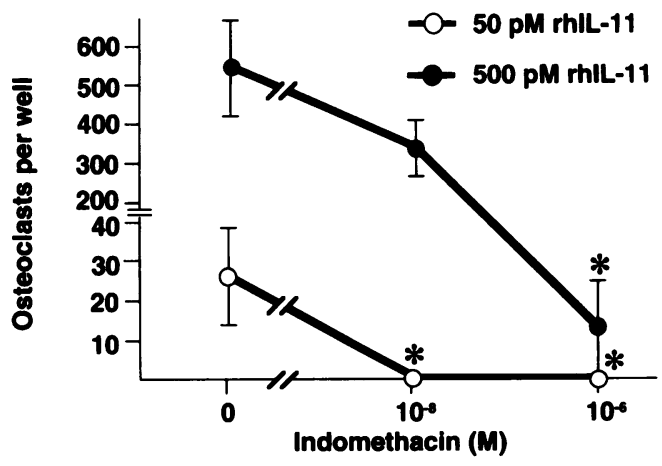

Figure 6. Effect of Indomethacin on IL-11-induced osteoclast formation. Cocultures of murine marrow cells and calvaria cells were maintained for $9 \mathrm{~d}$ in the absence $(O)$ or presence of the indicated amounts of indomethacin and rhIL-11. Data shown represent the mean \pm SD osteoclast number per well from four replicate cultures. ${ }^{*} P<0.05$ vs cultures maintained in 50 or 500 pM rhIL-11, but not treated with indomethacin. Data were analyzed by Kruskall-Wallis nonparametric ANOVA; Dunn's test was used to detect significant differences between means. 
Table V. Effect of Monoclonal Antibodies to IL-6 or IL-11 on Osteoclast Development in Murine Bone Marrow Cell Cultures

\begin{tabular}{|c|c|c|c|c|c|c|}
\hline \multirow[b]{2}{*}{ Antibody } & \multicolumn{2}{|c|}{ Sham } & \multicolumn{2}{|c|}{ ovx } & \multicolumn{2}{|c|}{ OVX $+E_{2}$} \\
\hline & $1,25 \mathrm{D}$ & PTH & $1,25 \mathrm{D}$ & PTH & 1,25D & PTH \\
\hline None & $180 \pm 37$ & $112 \pm 41$ & $466 \pm 54$ & $184 \pm 73$ & $191 \pm 28$ & $103 \pm 15$ \\
\hline IL-6 mAb & $230 \pm 57$ & $116 \pm 94$ & $180 \pm 28^{*}$ & $35 \pm 39^{*}$ & $187 \pm 47$ & $108 \pm 30$ \\
\hline $\mathrm{IL}-11 \mathrm{mAb}$ & $8 \pm 6^{*}$ & $13 \pm 12^{*}$ & $81 \pm 45^{*}$ & $25 \pm 19^{*}$ & $46 \pm 21^{*}$ & $30 \pm 38^{*}$ \\
\hline
\end{tabular}

Mice were either sham operated (sham) or ovariectomized. Ovariectomized animals were then left untreated (OVX) or were implanted with $10 \mu \mathrm{g}$ $17 \beta$-estradiol pellets $\left(\mathrm{OVX}+\mathrm{E}_{2}\right) .4 \mathrm{wk}$ after surgery, the animals were killed and bone marrow cells were cultured either in the presence of 10 $\mathrm{nM} 1,25(\mathrm{OH})_{2} \mathrm{D}_{3}(1,25 \mathrm{D})$ or $10 \mathrm{nM}$ parathyroid hormone (PTH). Parallel cultures received either no additional treatment (None), $36 \mu \mathrm{g} / \mathrm{ml}$ of a neutralizing monoclonal rat antibody to murine IL-6, or $6 \mu \mathrm{g} / \mathrm{ml}$ of the neutralizing monoclonal murine antibody to IL-11. Each value represents the mean \pm SD osteoclast number per well from triplicate cultures. ${ }^{*} P<0.01$ vs control cultures maintained in the absence of antibody (None).

\section{Acknowledgments}

The authors wish to thank P. Schendel, S. Goldman, and E. M. Alderman of Genetics Institute (Cambridge, MA) for advice and for providing the rhIL-11, rmIL-11, and the anti-IL-11 antibody; J. Abrams of DNAX Research Institute of Cellular and Molecular Biology (Palo Alto, CA) for providing the anti-IL-6 antibody; B. Conner for assistance with scanning electron microscopy; S. Knutson for technical assistance; N. Barker for the preparation of this manuscript; and Drs. Julie Glowacki, David Roodman, Hal Broxmeyer, and David Williams for critical review of the manuscript before its submission.

This work was supported by the National Institutes of Health (AR41313) and the Veterans Administration.

\section{References}

1. Metcalf, D. 1989. The molecular control of cell division, differentiation commitment and maturation in haemopoietic cells. Nature (Lond.). 339:27-30.

2. Dorshkind, K. 1990. Regulation of hemopoiesis by bone marrow stromal cells and their products. Annu. Rev. Immunol. 8:111-137.

3. Shadduck, R. K., A. Waheed, J. S. Greenberger, and T. M. Dexter. 1983. Production of colony stimulating factor in long-term bone marrow cultures. $J$. Cell Physiol. 114:88-92.

4. Hattersley, G., J. A. Kerby, and T. J. Chambers. 1991. Identification of osteoclast precursors in multilineage hemopoietic colonies. Endocrinology. 128:259-262.

5. Kurihara, N., C. Chenu, M. Miller, C. Civin, and G. D. Roodman. 1990 Identification of committed mononuclear precursors for osteoclast-like cells formed in long term human marrow cultures. Endocrinology. 126:2733-2741.

6. Klein, B., J. Wijdenes, X.-G. Zhang, M. Jourdan, J.-M. Boiron, J. Brochier, J. Liautard, M. Merlin, C. Clement, B. Morel-Fournier, et al. 1991. Murine anti-interleukin-6 monoclonal antibody therapy for a patient with plasma cell leukemia. Blood. 78:1198-1204.

7. Roodman, G. D., N. Kurihara, Y. Ohsaki, A. Kukita, D. Hosking, A. Demulder, J. F. Smith, and F. R. Singer. 1992. Interleukin 6. A potential autocrine/paracrine factor in Paget's disease of bone. J. Clin. Invest. 89:46-52.

8. Girasole, G., R. L. Jilka, G. Passeri, S. Boswell, G. Boder, D. C. Williams, and S. C. Manolagas. 1992. 17 $\beta$-estradiol inhibits interleukin-6 production by bone marrow-derived stromal cells and osteoblasts in-vitro: a potential mechanism for the antiosteoporotic effect of estrogens. J. Clin. Invest. 89:883-891.

9. Jilka, R. L., G. Hangoc, G. Girasole, G. Passeri, D. C. Williams, J. S. Abrams, B. Boyce, H. Broxmeyer, and S. C. Manolagas. 1992. Increased osteoclast development after estrogen loss: mediation by interleukin-6. Science (Wash. DC). 257:88-91.

10. Passeri, G., G. Girasole, R. L. Jilka, and S. C. Manolagas. 1993. Increased Interleukin- 6 production by murine bone marrow and bone cells after estrogen withdrawal. Endocrinology. 133:822-828.

11. Paul, S. R., Y. C. Yang, R. E. Donahue, S. Goldring, and D. A. Williams. 1991. Stromal cell-associated hematopoiesis: immortalization and characterization of a primate bone marrow-derived stromal cell line. Blood. 77:1723-1733.

12. Paul, S. R., F. Bennett, J. A. Calvetti, K. Kelleher, C. R. Wood, R. M.
O'Hara, Jr., A. C. Leary, B. Sibley, S. C. Clark, D. A. Williams, and Y.-C. Yang. 1990. Molecular cloning of a cDNA encoding interleukin 11, a stromal cell-derived lymphopoietic and hematopoietic cytokine. Proc. Natl. Acad. Sci. USA. 87:7512-7516.

13. Kawashima, I., J. Ohsumi, K. Mita-Honjo, K. Shimoda-Takano, H. Ishikawa, S. Sakakibara, K. Miyadai, and Y. Takiguchi. 1991. Molecular cloning of cDNA encoding adipogenesis inhibitory factor and identity with interleukin-11. FEBS (Fed. Eur. Biochem. Soc.) Lett. 283:199-202.

14. McKinley, D., Q. Wu, T. Yang-Feng, and Y.-C. Yang. 1992. Genomic sequence and chromosomal location of human interleukin-11 gene (IL11). Genomics. 13:814-819.

15. Musashi, M., Y. C. Yang, S. R. Paul, S. C. Clark, T. Sudo, and M. Ogawa. 1991. Direct and synergistic effects of interleukin 11 on murine hemopoiesis in culture. Proc. Natl. Acad. Sci. USA. 88:765-769.

16. Tsuji, K., S. D. Lyman, T. Sudo, S. C. Clark, and M. Ogawa. 1992. Enhancement of murine hematopoiesis by synergistic interactions between stee factor (ligand for $\mathrm{c}-\mathrm{kit}$ ), interleukin-11, and other early acting factors in culture. Blood. 79:2855-2860.

17. Musashi, M., S. C. Clark, T. Sudo, D. L. Urdal, and M. Ogawa. 1991. Synergistic interactions between interleukin-11 and interleukin-4 in support of proliferation of primitive hematopoietic progenitors of mice. Blood. 78:14481451.

18. Teramura, M., S. Kobayashi, S. Hoshino, K. Oshimi, and H. Mizoguchi. 1992. Interleukin-11 enhances human megakaryocytopoiesis in vitro. Blood. 79:327-331.

19. Hattersley, G., and T. J. Chambers. 1989. Calcitonin receptors as markers for osteoclastic differentiation: correlation between generation of bone-resorptive cells and cells that express calcitonin receptors in mouse bone marrow cultures. Endocrinology. 125:1606-1612.

20. Takahashi, N., H. Yamana, S. Yoshiki, G. D. Roodman, G. R. Mundy, S. J. Jones, A. Boyde, and T. Suda. 1988. Osteoclast-like cell formation and its regulation by osteotropic hormones in mouse bone marrow cultures. Endocrinology. 122:1373-1382.

21. Akatsu, T., N. Takahashi, N. Udagawa, K. Sato, N. Nagata, J. M. Moseley, T. J. Martin, and T. Suda. 1989. Parathyroid hormone (PTH)-related protein is a potent stimulator of osteoclast-like multinucleated cell formation to the same extent as PTH in mouse marrow cultures. Endocrinology. 125:20-27.

22. Takahashi, N., T. Akatsu, N. Udagawa, T. Sasaki, A. Yamaguchi, J. M. Moseley, T. J. Martin, and T. Suda. 1988. Osteoblastic cells are involved in osteoclast formation. Endocrinology. 123:2600-2602.

23. Akatsu, T., T. Tamura, N. Takahashi, N. Udagawa, S. Tanaka, T. Sasaki, A. Yamaguchi, N. Nagata, and T. Suda. 1992. Preparation and characterization of a mouse osteoclast-like multinucleated cell population. J. Bone Miner. Res. 7:1297-1306.

24. Suda, T., N. Takahashi, and T. J. Martin. 1992. Modulation of osteoclast differentiation. Endocr. Rev. 13:66-80.

25. Starnes, H. F., Jr., M. K. Pearce, A. Tewari, J. H. Yim, J.-C. Zou, and J. S. Abrams. 1990. Anti-IL-6 monoclonal antibodies protect against lethal Escherichia coli infection and lethal tumor necrosis factor- $\alpha$ challenge in mice. $J$. Immunol. 145:4185-4191.

26. Jilka, R. L. 1986. Parathyroid hormone-stimulated development of osteoclasts in cultures of cells from neonatal murine calvaria. Bone. 7:29-40.

27. Boyde, A., N. N. Ali, and S. J. Jones. 1985. Optical and scanning electron microscopy in the single osteoclast resorption assay. Scanning Microsc. 3:12591271. 
28. Chambers, T. J., P. M. McSheehy, B. M. Thomson, and K. Fuller. 1985. The effect of calcium-regulating hormones and prostaglandins on bone resorption by osteoclasts disaggregated from neonatal rabbit bones. Endocrinology. 116:234-239.

29. Shinar, D. M., and G. A. Rodan. 1990. Biphasic effects of transforming growth factor- $\beta$ on the production of osteoclast-like cells in mouse bone marrow cultures: the role of prostaglandins in the generation of these cells. Endocrinology. 126:3153-3158.

30. Akatsu, T., N. Takahashi, N. Udagawa, K. Imamura, A. Yamaguchi, K. Sato, N. Nagata, and T. Suda. 1991. Role of prostaglandins in interleukin-1-induced bone resorption in mice in vitro. J. Bone Miner. Res. 6:183-190.

31. Dinarello, C. A. 1989. Interleukin-1 and its biologically related cytokines. Adv. Immunol. 44:153-205.

32. Yoshida, H., S.-I. Hayashi, T. Kunisada, M. Ogawa, S. Nishikawa, H. Okamura, T. Sudo, L. D. Shultz, and S.-I. Nishikawa. 1990. The murine muta- tion osteopetrosis is in the coding region of the macrophage colony stimulating factor gene. Nature (Lond.). 345:442-444.

33. Felix, R., M. G. Cecchini, and H. Fleisch. 1990. Macrophage colony stimulating factor restores in vivo bone resorption in the op/op osteopetrotic mouse. Endocrinology. 127:2592-2594.

34. Wiktor-Jedrzejczak, W., A. Bartocci, A. W. Ferrante, Jr., A. Ahmed-Ansari, K. W. Sell, J. W. Pollard, and E. R. Stanley. 1990. Total absence of colonystimulating factor 1 in the macrophage-deficient osteopetrotic (op/op) mouse. Proc. Natl. Acad. Sci. USA. 87:4828-4832.

35. Kodama, H., M. Nose, S. Niida, and A. Yamasaki. 1991. Essential role of macrophage colony-stimulating factor in the osteoclast differentiation supported by stromal cells. J. Exp. Med. 173:1291-1294.

36. Shinar, D. M., M. Sato, and G. A. Rodan. 1990. The effect of hemopoietic growth factors on the generation of osteoclast-like cells in mouse bone marrow cultures. Endocrinology. 126:1728-1735. 